\title{
The Dinamap 1846SX automated blood pressure recorder: comparison with the Hawksley random zero sphygmomanometer under field conditions
}

\author{
Peter H Whincup, Nigel G Bruce, Derek G Cook, A Gerald Shaper
}

\begin{abstract}
Study objective-The aim was to compare the performance of the Dinamap 1846SX automated oscillometric blood pressure recorder with that of the Hawksley random zero sphygmomanometer during use under field study conditions.

Design-Two independent within subject measurement comparisons were made, one in adults and one in children, each conducted in three stages over several months while the Dinamap instruments were being used in epidemiological field surveys.
\end{abstract}

Setting-The studies were done in outpatients clinics (adults) and primary schools (children).

Participants -141 adults (20-85 years) and 152 children (5-7 years) took part.

Measurements and main results-In adults a pair of measurements was made with each instrument, the order alternating for consecutive subjects. In children one measurements was made with each instrument, in random order. Measurements with the Dinamap $1846 S X$ were higher than those with the random zero sphygmomanometer both in adults (mean difference $8.1 \mathrm{~mm} \mathrm{Hg}$; $95 \%$ CI 6.5 to $9.7 \mathrm{~mm}$ $\mathrm{Hg}$ ) and in children (mean difference 8.3 mm Hg; 95\% CI 6.9 to $9.7 \mathrm{~mm} \mathrm{Hg}$ ). Diastolic measurements were on average very similar both in adults and in children. The results were consistent at all three stages of both studies. The differences in systolic measurement were independent of blood pressure level. However, the extent of agreement in diastolic pressure depended on the diastolic blood pressure level; in both studies Dinamap diastolic measurements were higher at low diastolic pressures while random zero diastolic measurements were higher at high diastolic pressures.

Conclusions-Systolic measurements made with the Dinamap 1846 SX instrument are not directly comparable with those of the Hawksley random zero sphygmomanometer and are unlikely to be comparable with those of earlier Dinamap models. These differences have important implications for clinical practice and for comparisons of blood pressure measurement between epidemiological studies. However, the consistency of measurement by the Dinamap 1846 SX over time suggests that the instrument may have a place in standardised blood pressure measurement in the research setting.
The use of the sphygmomanometer in standardised blood pressure measurement raises several potential problems. Blood pressure measurement may vary between observers, ${ }^{1}$ and observer performance may vary over time, despite observer training. ${ }^{2}{ }^{3}$ Modified sphygmomanometers ${ }^{45}$ may reduce digit preference but do not necessarily eliminate observer bias in blood pressure measurement. By standardising the technical aspects of measurement and recording, automated blood pressure recorders may reduce these variations in blood pressure measurement. However, insufficient information is available on the performance of many of these instruments. ${ }^{6}$ The Dinamap automated blood pressure recorder (Critikon Inc), which uses the oscillometric method, ${ }^{7}$ is being increasingly used by investigators. The earlier Dinamap devices, particularly the 845 and 847 series, have been extensively studied in comparison with direct intra-arterial measurement ${ }^{7-17}$ and the mercury sphygmomanometer. ${ }^{18-23}$ However, relatively little attention has been given to the more recent Dinamap series. ${ }^{24} 25$ Moreover, few data are available on the accuracy of the instrument at different blood pressure levels ${ }^{26}$ and on the performance and reliability of the Dinamap in population based surveys. We report the results of two separate studies designed to compare the performance of the more recent Dinamap 1846SX automated blood pressure recorder with the Hawksley random zero sphygmomanometer. These studies, one in adults and one in children, were both carried out over several months while the Dinamap insruments were being used in two large population surveys. ${ }^{27} 28$

\section{Methods}

STUDY IN ADULTS

Subjects aged between 20 and 85 years attending a medical outpatient clinic were invited to participate. A total of 154 subjects took part. The study took place in three stages over a total of seven months. All measurements were made by two experienced observers, each of whom examined approximately half the subjects on each occasion. Both observers received training in auscultatory blood pressure measurement ${ }^{2}$ less than a week before the beginning of each stage of the study. Observer performance was examined after each training session with a standard test tape $^{2}$; all observers showed an average error within the recommended limits of one second $(2 \mathrm{~mm} \mathrm{Hg}$ ) in both systolic and diastolic recordings throughout the study. All measurements were made on the right arm with the subject 
seated after 5 minutes' rest. Four consecutive blood pressure measurements were taken at one minute intervals on each participant, two with the Dinamap 1846SX and two with the Hawksley random zero sphygmomanometer. The order in which the instruments were used was alternated for each subject, ensuring that numbers were balanced for each session. The Dinamap 1846SX had an initial inflation pressure of $180 \mathrm{~mm} \mathrm{Hg}$ and all results were recorded directly onto a printed output. A standard Hawksley random zero sphygmomanometer was used with an initial inflation pressure of $200 \mathrm{~mm} \mathrm{Hg}$. Diastolic pressure was recorded at the point of disappearance of Korotkow sounds (Phase V). The cuff sizes recommended by the manufacturer, which conform to the guidelines of the American Heart Association, ${ }^{29}$ were used on each occasion with both instruments.

\section{STUDY IN CHILDREN}

Children aged between five and seven years and attending three primary schools were invited to take part in this study. A total of 152 subjects took part. The study took place in three stages over a period of 10 months. All measurements were made by two experienced observers, each of whom made approximately half of the paired blood pressure measurements on each occasion. Training and testing in auscultatory blood pressure measurement was carried out as in the adult study. ${ }^{2}$ All measurements were made on the right arm with the subject seated after 5 minutes' rest. Two consecutive blood pressure measurements were taken one minute apart on each participant, one with a Dinamap 1846SX and one with a Hawksley random zero sphygmomanometer. The order of measurement was randomly allocated and balanced for each session. Both instruments were distinct from those used in the adult study. The Dinamap 1846SX was of identical specification; the Hawksley random zero instrument was fitted with a $20 \mathrm{~mm} \mathrm{Hg}$ cam, enabling a lower initial inflation pressure of $180 \mathrm{~mm} \mathrm{Hg}$ to be used. Diastolic pressure was recorded at the point of muffling of Korotkow sounds (Phase IV) because of the difficulty in recording Phase V accurately in children. ${ }^{29}$ The cuff bladder size used for each instrument followed the recommendations of Prineas and colleagues, ${ }^{30}$ closely related to those of the American Heart Association, ${ }^{29}$ to ensure that cuff bladder length was at least $90 \%$ of arm circumference and the cuff bladder width at least $120 \%$ of arm diameter in every case. Two sizes of cuff were available for use with each instrument in the study; cuff bladder dimensions for the Dinamap were $15 \mathrm{~cm} \times 9 \mathrm{~cm}$ (child), $22 \mathrm{~cm} \times$ $12 \mathrm{~cm}$ (adult), and for the Hawksley were $18 \mathrm{~cm} \times$ $9 \mathrm{~cm}$ (child), $23 \mathrm{~cm} \times 12 \mathrm{~cm}$ (adult). In a separate study, a systematic difference in blood pressure measurement between the two cuffs used with each instruments was observed, with child cuffs recording systematically higher blood pressures than the adult cuffs. ${ }^{31}$ Accordingly, all results were standardised to the child cuff size as described. ${ }^{32}$ However, the results presented here are very similar whether or not such standardisation is employed.
USE OF INSTRUMENTS IN FIELD STUDIES

Between the first and third set of comparisons described here, both Dinamap instruments were used in epidemiological field surveys, each instrument making more than 10000 blood pressure measurements and being calibrated daily during use against standard mercury columns at $0,50,100,150$, and $200 \mathrm{~mm} \mathrm{Hg}$. No evidence of drift in static calibration requiring adjustment was detected in either of the two instruments. In the adult study, the instrument failed to record measurements in only two subjects out of 2615, while in the child study measurements were obtained in all but seven of 4116 subjects $(0.17 \%)$, usually as a result of the child moving. The Hawksley instruments were held specifically for the comparative studies over this period and made no other measurements.

\section{STATISTICAL METHODS}

Mean differences between instruments-In the adult study results are based on the means of the pairs of readings carried out with each instrument in each subject; in the study of children, results are based on single readings. The comparisons between instruments reported are all based on within subject differences, presented as Dinamap measurement minus Hawksley measurement throughout.

Blood pressure level-Blood pressure level for each subject is calculated as the mean of all readings carried out in that subject using both Dinamap and Hawksley instruments. Adjustments for the order in which the machines were used for each subject were made because blood pressure tends to fall with succesive measurements. Relationships between the difference between measurements by the two instruments and the mean recorded blood pressure were examined using standard multiple linear regression techniques. Comparisons of measurements at different sessions were examined using a one way analysis of variance.

\section{Results}

Results are presented for all 152 subjects in the children's study. In the adult study results are presented for $141(93 \%)$ subjects. Thirteen subjects with incomplete data have been excluded. The characteristics of subjects allocated to different order of measurement are presented in the table. In the adult study there was a difference in the age and sex distribution of the two groups, with subjects measured first with the Hawksley

Characteristics of subjects by order of measurement. Values are mean ( $S E)$.

\begin{tabular}{|c|c|c|c|c|}
\hline \multirow[b]{2}{*}{$\begin{array}{l}\text { Number } \\
\text { Age (years) } \\
\text { Sex ( } \% \text { male) } \\
\text { Observer ( } \% \text { each) } \\
\text { SBP (mean of both readings) } \\
\text { DBP (mean of both readings) }\end{array}$} & \multicolumn{2}{|c|}{ Dinamap first } & \multicolumn{2}{|c|}{ Hawksley first } \\
\hline & $\begin{array}{l}71 \\
51 \cdot 8 \\
45 \\
51 / 49 \\
135 \cdot 9 \\
78 \cdot 4\end{array}$ & $\begin{array}{l}(1 \cdot 9) \\
(3 \cdot 0) \\
(1 \cdot 6)\end{array}$ & $\begin{array}{l}\text { study } \\
70 \\
57 \cdot 0 \\
59 \\
56 / 44 \\
135 \cdot 8 \\
76 \cdot 4\end{array}$ & $\begin{array}{l}(2 \cdot 0) \\
\\
(2 \cdot 6) \\
(1 \cdot 5)\end{array}$ \\
\hline $\begin{array}{l}\text { Number } \\
\text { Age (years) } \\
\text { Sex (\% male) } \\
\text { Observer ( } \% \text { each) } \\
\text { SBP (mean of both readings) } \\
\text { DBP (mean of both readings) }\end{array}$ & $\begin{array}{l}74 \\
6 \cdot 32 \\
52 \\
50 / 50 \\
96 \cdot 4 \\
58 \cdot 2\end{array}$ & $\begin{array}{r}\text { Chil } \\
(0 \cdot 08) \\
\\
(1 \cdot 2) \\
(0 \cdot 8)\end{array}$ & $\begin{array}{l}\text { study } \\
78 \\
6 \cdot 31 \\
54 \\
47 / 53 \\
96 \cdot 4 \\
57 \cdot 1\end{array}$ & $\begin{array}{l}(0 \cdot 08) \\
(1 \cdot 1) \\
(0 \cdot 7)\end{array}$ \\
\hline
\end{tabular}


being older and having a greater predominance of males. However, adjustment for these factors had no important effect on the measurement differences between the instruments. The characteristics of the randomised groups in the study of children are very similar. All results were examined for each observer separately. No important differences between observers were found and results are therefore presented without observer adjustment.

MEAN SYSTOLIC PRESSURE DIFFERENCES BETWEEN INSTRUMENTS AND THEIR RELATIONSHIPS TO SYSTOLIC BLOOD PRESSURE LEVEL

Systolic blood pressure measurements were markedly higher with the Dinamap instrument than the Hawksley instrument both in adults (mean difference $8.1 \mathrm{~mm} \mathrm{Hg} ; 95 \%$ CI 6.5 to $9.7 \mathrm{~mm} \mathrm{Hg} ; \mathrm{p}<0.0001$ ) and in children (mean difference $8.3 \mathrm{~mm} \mathrm{Hg} ; 95 \% \mathrm{CI} 6.9$ to $9.7 \mathrm{~mm} \mathrm{Hg}$; $\mathrm{p}<0.0001$ ).

The relationships between these systolic blood pressure differences between instruments and systolic blood pressure level are presented in figure 1. Systolic differences between instruments are not importantly influenced by blood pressure level either in adults or in children; regression coefficients, representing the change in systolic blood pressure difference between instruments in $\mathrm{mm} \mathrm{Hg}$ for each $1 \mathrm{~mm} \mathrm{Hg}$ change in systolic blood pressure level, are 0.046 (standard error 0.035, $\mathrm{p}=0.20$ ) for adults and 0.013 (standard error $0.072, p=0.85)$ for children.

MEAN DIASTOLIC PRESSURE DIFFERENCES BETWEEN INSTRUMENTS AND THEIR RELATIONSHIPS TO DIASTOLIC BLOOD PRESSURE LEVEL

Mean differences in diastolic pressure between the Dinamap and Hawksley instruments are very small, both in adults (mean difference $0.2 \mathrm{~mm} \mathrm{Hg}$; $95 \% \mathrm{CI} 1.2$ to $1.6 \mathrm{~mm} \mathrm{Hg}$ ) and in children (mean difference $-0.2 \mathrm{~mm} \mathrm{Hg} ; 95 \%$ CI 1.8 to $1.4 \mathrm{~mm}$

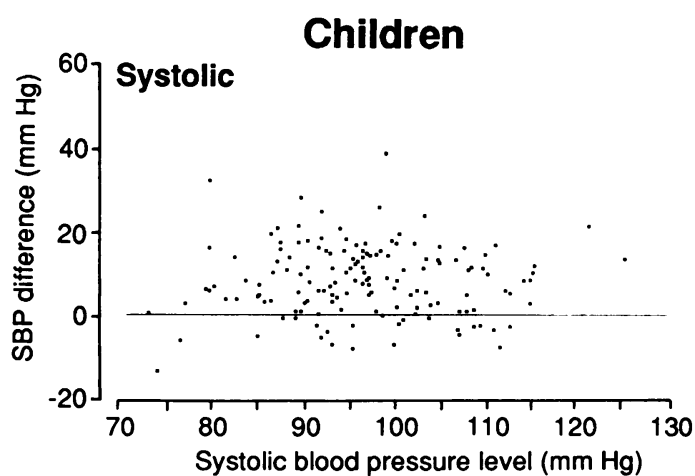

Figure 1 Blood pressure level and differences in blood pressure measurement between Dinamap $1846 S X$ and Hawksley instruments. Systolic and diastolic Systolic and diastolic
differences (DinamapHawksley) are presented for individual subjects in both adult and child studies. $S B P=$ systolic studies. $S B P=$ systolic
blood pressure; $D B P=$ diastolic blood pressure.

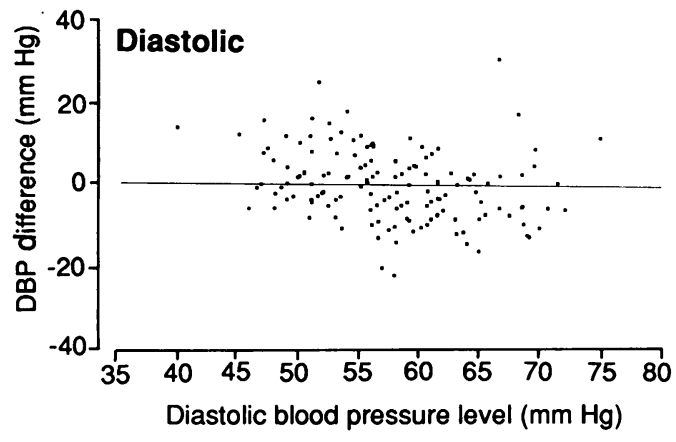

$\mathrm{Hg}$ ), suggesting a high level of overall agreement in diastolic pressure between the instruments. The relationships between diastolic differences between instruments and diastolic blood presure level are presented in figure 1 . There appears to be a negative relationship between blood pressure level and blood pressure difference between instruments; at high diastolic pressure levels Dinamap readings are lower than Hawksley readings, whereas at low diastolic pressure levels the reverse is true. This appears to be the case in both the study of adults and the study of children. Regression coefficients, which represent the change in diastolic blood pressure difference between instruments ( $\mathrm{mm} \mathrm{Hg}$ ) for each $\mathrm{mm} \mathrm{Hg}$ change in diastolic blood pressure level, are -0.189 (SE 0.051, p=0.0003) for adults and -0.324 (SE $0.102, p=0.002$ ) for children. The strengths of these relationships suggest that a 10 $\mathrm{mm} \mathrm{Hg}$ rise in diastolic blood pressure level is accompanied by a fall in Dinamap-Hawksley differences of $1.9 \mathrm{~mm} \mathrm{Hg}$ for adults and $3.1 \mathrm{~mm}$ $\mathrm{Hg}$ for children. The slopes of these relationships between blood pressure level and measurement differences are not markedly different in the two studies (test for difference between slopes, $\mathrm{p}=0 \cdot 25)$. However, the positions of these slopes are quite different, as indicated by the difference between the two studies in the diastolic blood pressure level at which there is complete agreement between instruments, $79 \mathrm{~mm} \mathrm{Hg}$ in the adult study and $57 \mathrm{~mm} \mathrm{Hg}$ in the child study. This difference is highly statistically significant $(\mathrm{p}<0.001)$

\section{BLOOD PRESSURE DIFFERENCES BETWEEN}

INSTRUMENTS OVER TIME

The differences in blood pressure measurement between the Dinamap and Hawksley instruments at each of the three examination sessions are presented in fig 2. Variations in measurement differences between sessions were more marked
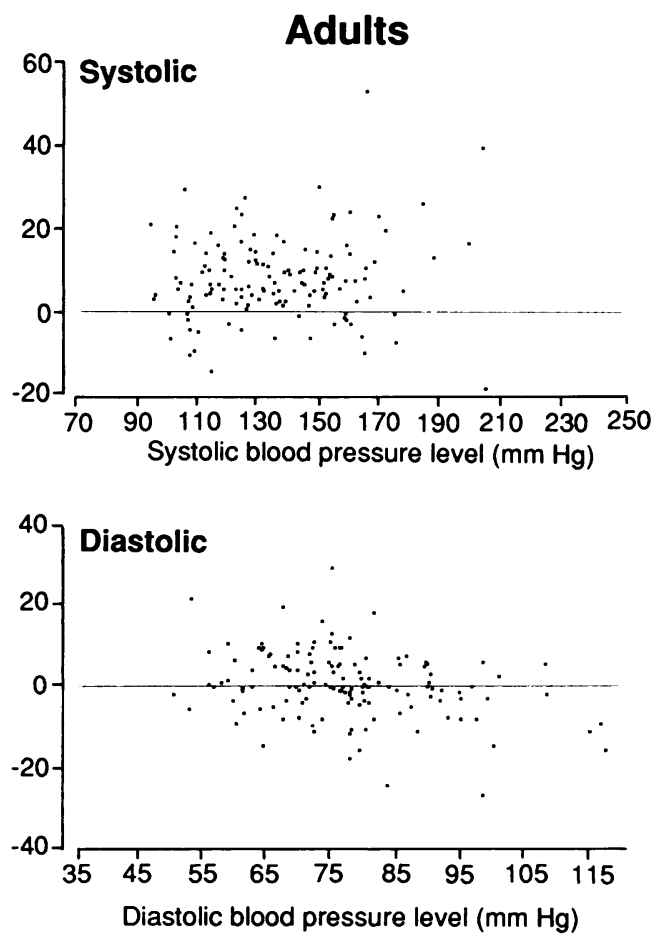
Figure 2 Differences in blood pressure measurement between Dinamap 1846SX and Hawksley instruments (Dinamap-Hawksley) by session of examination. Means and $95 \%$ confidence intervals are shown. SBP = systolic blood pressure; $D B P=$ diastolic blood pressure.
Figure 3 Review of published comparisons of systolic and diastolic blood pressure measurement between Dinamap oscillometric recorders and sphygmomanometers. The name of the first author, the number of the Dinamap model, and the type of sphygmomanometer

( $S S=$ standard mercury sphygmomanometer;

$R Z=$ random $z$ ero

sphygmomanometer; $M M=$ mercury manometer) are given in each case. The mean Dinamapsphygmomanometer confidence intervals where possible, is shown for each study. ch $=$ child, ad $=$ adult.
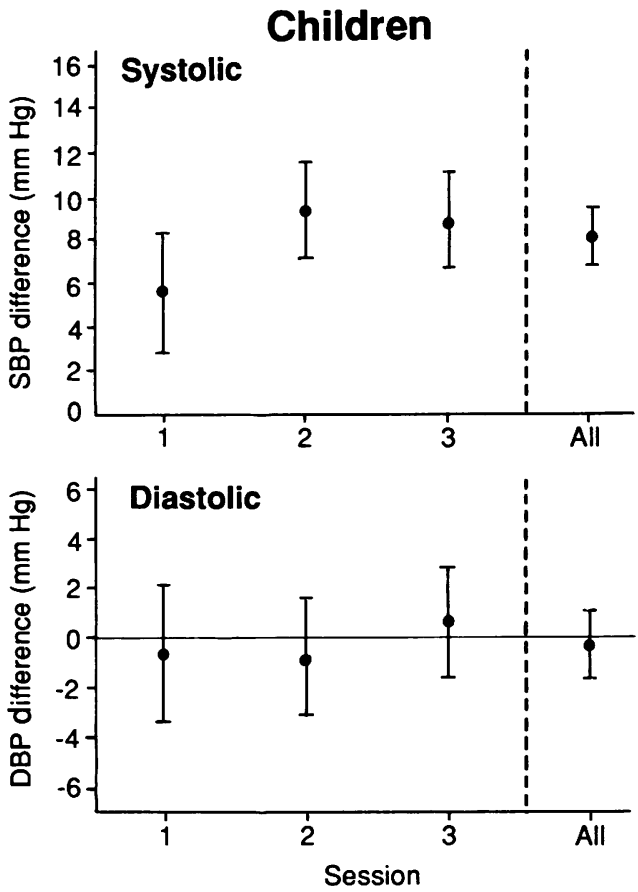

for systolic than for diastolic pressure in both adults and children. In the case of adults, mean Dinamap-Hawksley systolic differences increased by a total of $2.8 \mathrm{~mm} \mathrm{Hg}$ between the first and third sessions. However, these changes could easily be due to chance $(p=0.42)$. There was also an increase in systolic differences between the first and third stages of the children's study (by 3.5 $\mathrm{mm} \mathrm{Hg}$ ) but although the difference approached the conventional level of statistical significance $(p=0.064)$ there was no indication of a consistent trend. For diastolic pressure the agreement of Dinamap and Hawksley measurements was extremely consistent over the period of examination in both adult and child studies.

\section{Discussion}

This report is among the first describing the performance of a contemporary automated oscillometric blood pressure recorder, the Dinamap 1846SX, under field survey conditions. The populations studied encompass a wide range of ages and blood pressure levels, with over $10 \%$ of adult subjects being hypertensive (systolic blood pressure $\geqslant 160 \mathrm{~mm} \mathrm{Hg}$ or diastolic blood pressure $\geqslant 95 \mathrm{~mm} \mathrm{Hg}$ ).
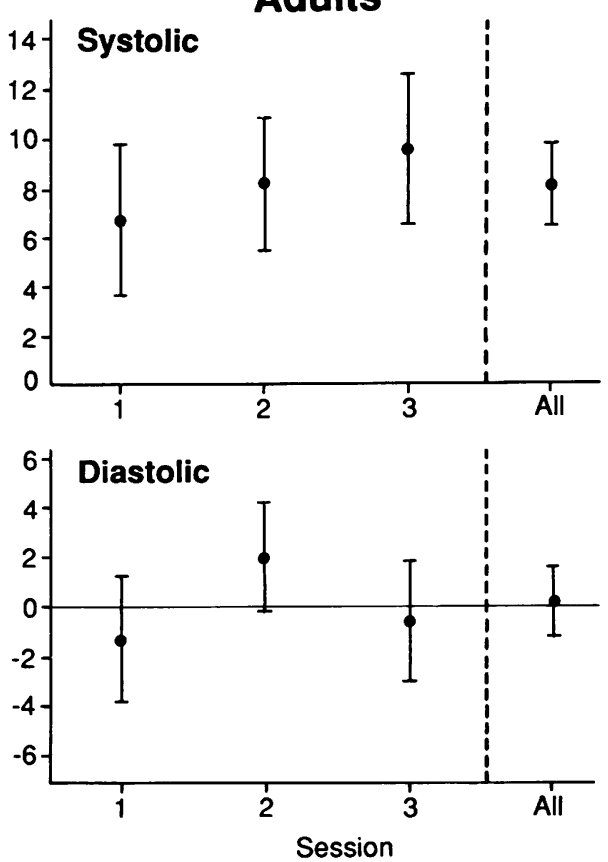

OVERALL DIFFERENCES BETWEEN DINAMAP AND HAWSKLEY INSTRUMENTS

The Dinamap 1846SX recorded systolic pressures consistently higher than those obtained by the Hawksley instrument in both adults and children. Diastolic pressures, by contrast, showed a high level of overall agreement between instruments. Although these results are based on studies using a single instrument in each case, the observations of the two studies are strikingly consistent. Placed in the context of previous reported comparisons between Dinamap and auscultatory instruments (fig 3 ), the results are in close agreement with the one previous study involving the Dinamap $1846 \mathrm{SX}, 25$ and also with the results of a study of the Dinamap 8100, a closely related model. ${ }^{18}$ The most striking feature of this figure is that whereas systolic measurements made by the earlier Dinamap 845 model match auscultatory measurements closely, those of the 8100 and $1846 \mathrm{SX}$ exceed auscultatory measurements by several millimetres. Different reference sphygmomanometers were used in these studies, with some using the standard mercury instrument and others the Hawksley random zero instrument. However, the

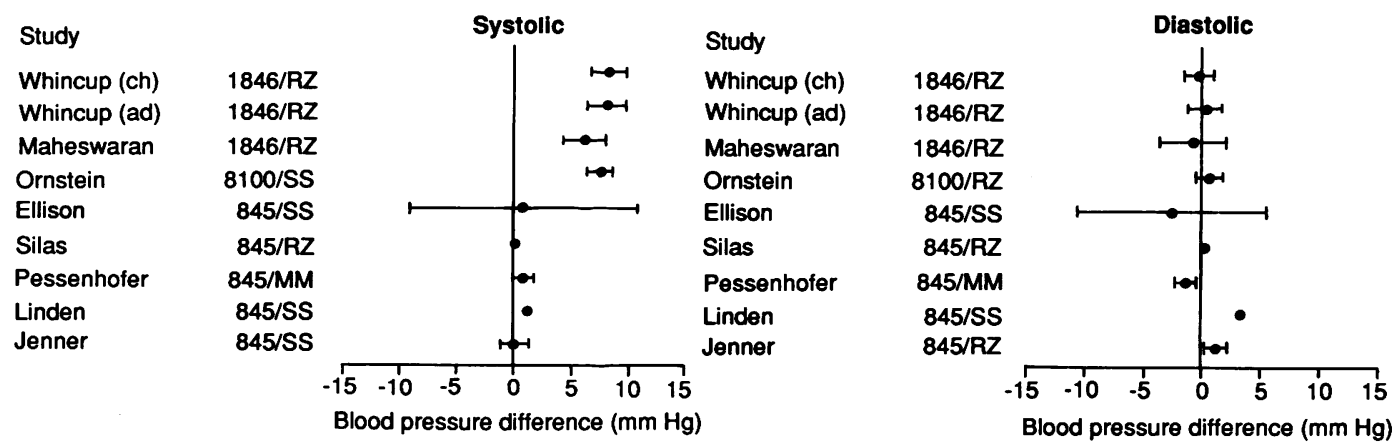


differences shown in fig 3 appear to be independent of the type of reference sphygmomanometer used and the findings are therefore unlikely to be explained by the differences in blood pressure measurement between the standard and random zero instruments which have been reported. ${ }^{32-34}$ The most likely explanation of the findings in fig 3 is that systolic measurement by the Dinamap 1846SX and 8100 models is not comparable with that of the earlier 845 model, possibly as a result of changes in programming in the newer models. For diastolic pressure, by contrast, measurements made by all Dinamap models agree closely with those of sphygmomanometers (fig 3). The relationship between Dinamap 1846SX measurement and direct intra-arterial measurements remains uncertain. Only one study, conducted in premature neonates, has compared Dinamap 1846SX measurements with direct intra-arterial measurement. ${ }^{24}$ In that study, the Dinamap 1846SX underestimated directly measured systolic pressure by an average of $4.9 \mathrm{~mm} \mathrm{Hg}$, a finding which contrasts with earlier reports on the 845 and 847 models, which showed good agreement with direct intra-arterial measurement. ${ }^{9-11}$ These contradictory findings emphasise the need for further evaluation of the Dinamap $1846 \mathrm{SX}$, particularly in relation to direct intra-arterial pressure measurement.

INSTRUMENT DIFFERENCES IN BLOOD PRESSURE MEASUREMENT AND THEIR RELATIONSHIP TO BLOOD PRESSURE LEVEL

A negative relationship between diastolic pressure level and diastolic differences between the two instruments was observed in both adult and child studies. This has not previously been reported with the Dinamap 1846SX, ${ }^{25}$ although an earlier study suggested that the Dinamap 845 might overestimate pressures at low blood pressure levels. ${ }^{17}$ The basis for the finding remains uncertain, but it seems unlikely that diastolic blood pressure level per se is responsible. The marked difference in the position of the slopes relating diastolic blood pressure level and instrument differences in the adult and childhood studies argues strongly against a uniform relationship between blood pressure level and instrument differences. This suggests that a factor other than blood pressure level is responsible for the relationship.

CONSISTENCY OF DINAMAP PERFORMANCE OVER TIME

The Dinamp instrument proved robust, with no mechanical or electronic component failures despite frequent dismantling and removal. However, the condition of the rubber O-rings sealing the pressure hose junctions could deteriorate quite rapidly with repeated cuff changes and dismantling of the instrument and careful monitoring was required to ensure that these remained in satisfactory condition. The static calibration testing of both instruments remained stable throughout the periods of study. Moreover, the studies described in this report provide no strong evidence of drift in blood pressure measurement with either instrument, despite extensive use, an experience consistent with that of Ellison et al with the Dinamap $845 .^{19}$

IMPLICATIONS FOR USE OF THE DINAMAP 1846SX INSTRUMENT

The large systematic difference in systolic measurement between the Dinamap 1846SX and the random zero sphygmomanometer, exceeding the $5 \mathrm{~mm} \mathrm{Hg}$ limits advocated by the Association for the Advancement of Medical Instrumentation, ${ }^{35}$ could lead to the overdiagnosis of hypertension if systolic criteria based on auscultatory measurements are applied to measurements made by the Dinamap 1846SX. The results of this study therefore suggest that the Dinamap 1846SX is unsuitable as a direct substitute for the sphygmomanometer in a clinical setting. In the research setting (both in population studies and clinical trials), the ability to make consistent measurements in all circumstances is particularly important. Our data suggest that the Dinamap 1846SX fulfils this criterion. Systematic differences in blood pressure measurement from the standard sphygmomanometer are of less importance in the research context because the main outcome of a research investigation will normally be based on blood pressure comparisons conducted within the study. However, comparisons between studies using the Dinamap 1846SX and other instruments are inadvisable unless differences in measurement between these instruments are taken into account.

Addendum-Since this paper was prepared, another report has provided evidence of systematic differences in systolic blood pressure measurement (and possibly also diastolic measurement) between the Dinamap 1846SX and ausculatory instruments. ${ }^{36}$

We thank the patients, parents and children who participated in this study. The contributions of Catherine Bond RGN, Sarah Burke RGN RM, Stephanie Kershaw RGN, Madeleine St Clair RGN, Dave Macfarlane BA and Andy Thomson BA are gratefully acknowledged.

The studies were supported by grants from the Medical Research Council, British Heart Foundation, Wellcome Trust, and Scottish Hospital Endowment Research Trust.

1 Rose GA, Blackburn $\mathrm{H}$, Gillum RF, Prineas RJ. Cardiovascular survey methods. Geneva: World Health Organization, 1982: 78-88.

2 Rose G. Standardisation of observers in blood pressure measurement. Lancet 1965; i: $673-4$.

measurement. Lancet 1965; i: 673-4.
3 Bruce NG, Shaper AG, Wannamethee G, Walker M. Observer bias in blood pressure studies. $尹$ Hypertens 1988 ; Observer b. $375-80$.

4 Garrow JS. A zero muddler for unprejudiced sphygmomanometry. Lancet 1963; ii: 1205 .

manometry. Lancet 1963; ii: 1205.
Rose GA, Holland WW, Crowley EA. A sphygmomanometer for epidemiologists. Lancet 1964, ii: 296-200. manometer for epidemiologists. Lancet 1964, it: 296-200. Olood pressure measuring devices. BMF 1987; 294: 1245-6. blood pressure measuring devices. $B M 71987$; 294: $1245-6$.
Ramsey $M$. Non-invasive automatic determinants of mean Ramsey M. Non-invasive automatic determinants of mean
arterial pressure. Med Biol Eng Comput 1979; 17: 11-18. arterial pressure. Med Biol Eng Comput 1979; 17: 11-18.
Park MK, Menard SM. Accuracy of blood pressure 8 Park MK, Menard SM. Accuracy of blood pressure measurement by the Dinamap monit
children. Pediatrics $1987 ; 79: 907-14$.

9 Pellegrini-Caliumi G, Agostino R, Naderi G, et al. Evaluation of an anterior oscillometric method and of various cuffs for the measurement of arterial blood pressur in the neonate. Acta Paediatr Scand 1982; 71: 791-7.

10 Colan S, Fujii A, Borow K, et al. Non-invasive determination of systolic, diastolic and end-systolic blood pressure in neonates, infants and young children comparisons with central aortic pressure measurements. Am 7 Cardiol 1983; 52: 867-75. 
11 Borow KM, Newburger JW. Non-invasive estimation of central aortic pressure using the oscillometric method for analysing systemic artery pulsatile flow: comparative study of indirect systolic, diastolic and mean arterial pressure with simultaneous direct central aortic pressure measurements. Am Heart f 1982; 103: 879-86.

12 Kimble KJ, Darnall RAJ, Yelderman M, Ariagno RL, Ream AK. An automated oscillometric technique for estimating arterial pressure in critically ill newborns. Anesthesiology 1981; 54: 423-5.

13 Yelderman M, Ream AK. Indirect measurements of mean blood pressure in the anaesthesized patient. Anesthesiology 1979; 50: 253-6.

14 Hutton P, Dye J, Prys-Roberts C. An assessment of the Dinamap 845. Anaesthesia 1984; 39: 261-7.

15 Rutten AJ, Ilsley AH, Skowronski GA, Runciman WB. A comparative study of the measurement of mean arterial blood pressure using automatic oscillometers, arterial cannulation and auscultation. Anaesth Intensive Care 1986; 14: 58-65.

16 Friesen RH, Lichtor JL. Indirect measurement of blood pressure in neonates and infants utilizing an automatic pressure in neonates and infants utilizing an automatic
non-invasive oscillometric monitor. Anesth Analg 1981; 60: non-in.

17 Johnson CJH, Kerr JH. Automatic blood pressure monitors. A clinical evaluation of five models in adults. Anaesthesia 1985; 40: 471-8.

18 Ornstein S, Markert G, Litchfield L, Zemp L. Evaluation of the Dinamap blood pressure monitor in an ambulatory primary care setting. $f$ Fam Pract 1988; 26: 517-21.

19 Ellison RC, Gamble WJ, Taft DS. A device for the automatic measurement of blood pressure in epidemiologic studies. Am ₹ Epidemiol 1984; 120: 542-9.

20 Silas JH, Barker AT, Ramsay LE. Clinical evaluation of Dinamap 845 automated blood pressure recorder. $\mathrm{Br} \mathrm{Heart}$ f 1980; 43: 202-5.

21 Pessonhofer $\mathrm{H}$. Single cuff comparison of two methods for indirect measurement of arterial blood pressure: standard auscultatory method versus automatic oscillometric method. Basic Res Cardiol 1986; 781: 101-9.

22 Linden W, Wright JM. Lack of comparability of two automated blood pressure monitors in a hypertensive population. Clin Invest Med 1986; 9: 71-5.

23 Jenner DA, Beilin LJ, Vandogen R. A comparison of blood pressure measurements obtained with the Dinamap 845XT, the standard mercury sphygmomanometer and the London School of Hygiene device. Clin Exp Hypertens $(A)$ 1988; 10: $575-88$.
24 Wareham JA, Haugh LD, Yeager SB, Horbar JD. Predicition of arterial blood pressure in the premature neonate using the oscillometric method. Am $\mathcal{f}$ Dis Child 1987; 141: 1108-10.

25 Maheswaran R, Zezulka AV, Gill JS, Beevers M, Davies P Beevers DG. Clinical evaluation of the Copal UA-251 and the Dinamap 1846SX automatic blood pressure monitors. $f$ Med Eng Technol 1988; 12: 160-3.

26 Bland JM, Altman DG. Statistical methods for assessing agreement between two methods of clinical measurement. Lancet 1986; i: $307-10$

27 Whincup PH, Cook DG, Shaper AG, Macfarlane DJ, Walker M. Blood pressure in British children: associations with adult blood pressure and cardiovascular mortality. Lancet 1988; ii: 890-3.

28 Bruce NG, Cook DG, Shaper AG, Thomson AG. Geographical variation in blood pressure in British men and women. f Clin Epidemiol 1990; 43: 385-98.

29 Frohlich ED, Grim C, Labarthe DR, et al. Recommendations for human blood pressure determinations by sphygmomanometers. Report of a special task force appointed by the Steering Committee, special task force appointed by the Steering Committee, Ame.

30 Prineas RJ, Gillum RF, Hirobe H, Hannan PJ. The Minneapolis children's blood pressure study. Part 1: standards of measurement for children's blood pressure. Hypertension 1980; 2 (suppl 1): 18-24.

31 Whincup PH, Cook DG, Shaper AG. Blood pressure measurement in children: the importance of cuff size. $\mathcal{J}$ Hypertens 1989; 7: 845-50.

32 O'Brien E, Mee F, Atkins N, O'Malley K. Inaccuracy of the Hawksley random zero sphygmomanometer. Lancet 1991 336: $1465-8$.

33 De Gaudemaris R, Folsam AR, Prineas RJ, Leupker RV. The random-zero versus the standard mercury sphyomomanometer: a systematic blood pressure difference. Am $\mathcal{A}$ Epidemiol 1985; 121: 282-90.

34 Evans JG, Prior IAM. Experience with the random-zero sphygmomanometer. Br F Prev Soc Med 1970; 24: 10-15.

35 Association for the Advancment of Medical Association for the Advancment of Medical
Instrumentation. Recommendations for electronic or Instrumentation. Recommendations for electronic or
automated sphygmomanometers. Arlington, Virginia: AAMI, 1987 .

36 Weaver MG, Park MK, Lee D-H. Differences in blood pressure level obtained by ausculatory and oscillometric methods. Am $\mathcal{F}$ Dis Child 1990; 144: 911-4. 